\title{
Relative Economic Performance and the Incumbent Vote: A Reference Point Theory
}

\author{
Selim Erdem Aytaç, Koç University
}

How can voters make sense of economic outcomes they observe when deciding whether to reelect the incumbent? I propose a reference point theory of economic voting that emphasizes voters' need for reference points when evaluating incumbents' performance. Consideration of economic outcomes during the incumbent's term relative to recent past outcomes in the country and in a cross-national perspective provides two such reference points, enabling a better assessment of incumbent competence. Analyses of 475 elections in 62 countries over 40 years provide evidence for my theory. Incumbents who preside over relatively better (worse) economic outcomes in domestic and international contexts are rewarded (punished) at the polls, regardless of election-year performance. I also show that cross-national benchmarking is not a universal phenomenon and identify the conditions that are positively associated with the electoral salience of relative international performance. My theory and accompanying evidence highlight that economic voting is driven by incumbents' relative performance.

$\mathrm{n}$ a televised debate just ahead of the 2012 French presidential election, opposition candidate François Hollande questioned the competence of the incumbent president, Nicolas Sarkozy, in managing the economy by pointing out the standstill on growth. Sarkozy's response was to emphasize the positive performance of the French economy relative to that of other European and OECD countries. Similarly, two years earlier across the English Channel, then leader of the opposition, David Cameron, assailed the Labour government by stressing that Britain was one of the first countries into recession and one of the last out of it during the Great Recession of 2008-9. At the other edge of the continent, while Turkish Prime Minister Erdoğan was campaigning for his third consecutive term in 2011, he frequently compared his government's performance to that of his predecessors, making references to the period before his first term in office more than 10 years ago.

Why do politicians emphasize relative economic performance by engaging in such within-country temporal and crossnational comparisons? ${ }^{1}$ Do voters take relative performance into account when evaluating the incumbent government, and if they do, is domestic or international relative performance more important for its electoral prospects? Traditional approaches to economic voting largely sidestep such questions. It does not matter, for example, whether economic outcomes on the incumbent's watch contrast sharply with recent past outcomes in the country or whether his or her tenure coincides with a global expansion or recession period. Voters are assumed to be "memoryless" in the sense that they forget about past outcomes and only focus on the most recent period. Moreover, they treat their national economies as if they exist in a vacuum, isolated from trends in the global economy. ${ }^{2}$ The premise is that a given economic outcome corresponds to the same level of performance across different countries and time periods and, hence, should have similar electoral implications. Accordingly, it is not clear why a French voter would take into account the performance of the French economy vis-àvis other economies of Europe or why a Turkish voter would think about how Erdoğan performed relative to past incumbents.

Selim Erdem Aytaç (saytac@ku.edu.tr) is an assistant professor in the Department of International Relations at Koç University, Rumelifeneri Yolu, Sarıer 34450, Istanbul, Turkey.

Data and supporting materials necessary to reproduce the numerical results in the paper are available in the JOP Dataverse (https://dataverse.harvard.edu /dataverse/jop). An online appendix with supplementary material is available at http://dx.doi.org/10.1086/693908.

1. Throughout the paper I refer to within-country temporal comparisons as "domestic comparisons" and to cross-national comparisons as "international comparisons."

2. Recently a number of scholars have paid attention to this second assumption by assessing the impact of the international economic context on election results (see, e.g., Campello and Zucco 2016; Kayser and Peress 2012; Leigh 2009). However, these studies focus on only one aspect of relative performance (the international one), ignoring the domestic context.

The Journal of Politics, volume 80, number 1. Published online October 17, 2017. http://dx.doi.org/10.1086/693908

(C) 2017 by the Southern Political Science Association. All rights reserved. 0022-3816/2018/8001-0002\$10.00 
I propose a reference point theory that revisits how we think about economic voting by focusing on incumbents' relative performance. My fundamental premise is that the relationship between economic outcomes and support for the incumbent cannot be properly understood without a domestically and internationally comparative framework. Voters need reference points to interpret economic outcomes and evaluate the incumbent's performance in managing the economy. An extension to the competence model of retrospective voting (Alesina and Rosenthal 1995; Persson and Tabellini 1990) suggests that consideration of economic outcomes during the incumbent's term relative to recent past outcomes in the country (domestic comparison) and in a cross-national perspective (international comparison) provides voters with two such reference points. Thus, whether a given economic outcome corresponds to good or poor performance depends on the reference points and comparisons voters employ. In the anecdotes given earlier, politicians emphasized relative performance because voters' evaluations of the incumbent's record are shaped by it.

The macro-level implication of my argument is that incumbents who preside over relatively better (worse) economic outcomes in domestic and international comparisons will be rewarded (punished) in elections. This prediction should hold independent of absolute levels of economic performance, for example, election-year growth. To test this prediction I construct an original data set of economic voting that includes measures of relative domestic and international performance for 475 national-level executive elections in 62 countries from 1965 to 2014. I show that measures of both domestic and international relative performance are significant predictors of incumbent support at the polls, and election-year growth ceases to be a significant correlate of incumbent support once we account for relative performance. The analyses also suggest that when evaluating relative domestic performance, voters pay attention to differences in economic outcomes between different incumbency terms rather than year-to-year comparisons; a result that is consistent with the competence model. There are some conditions associated with the electoral salience of relative international performance, however. In line with my theoretical predictions, I observe the electoral effect of relative international performance only in countries with highly educated populations, and this effect strengthens as the level of a country's international trade intensity increases.

By offering a unified perspective that considers relative domestic and international performance simultaneously, the theory and supporting evidence have significant implications for understanding electoral accountability through economic voting. The omission of a fully comparative framework, which characterizes the state of the art in the retrospective voting literature, is likely to result in invalid inferences about how vot- ers evaluate incumbents. Voters' past experiences shape their expectations of what good or poor performance would correspond to; thus it is essential to take into account recent past outcomes that voters faced when predicting their responses to new outcomes. In addition, my analyses build upon the nascent literature that emphasizes international comparisons for evaluating incumbents' performance by showing that the reported results do not extend to developing democracies with lower levels of average education - cross-national benchmarking does not seem to be a universal phenomenon but rather seems limited to voters in advanced democracies where availability of information about international economic outcomes is likely to be higher.

\section{RELATIVE PERFORMANCE AND THE ECONOMIC VOTE}

A review of the economic voting literature reveals that there are a only handful of studies that employ relative measures of economic conditions as explanatory variables. Even though these studies have contributed significantly to our understanding of how electoral accountability works, they do not fully capture the electoral consequences of relative economic performance.

Campello and Zucco (2016), Kayser and Peress (2012), Leigh (2009), and Powell and Whitten (1993), for example, examine the effect of relative international performance on incumbents' electoral fortunes but do not consider the domestic aspect of relative performance. ${ }^{3}$ A potential explanation for the omission of relative domestic performance in empirical studies might be that the most popular measure of economic performance, GDP growth, is already thought to be a comparative measure. After all, GDP growth shows how the GDP stands today in comparison to an earlier period. But this logic is flawed as every economic measure needs some reference point for evaluation - for example, what can we make of the information " $r \%$ growth rate in country $\mathrm{X}$ in year Y" without proper context? This is the rationale for recent interest in the literature on cross-national benchmarking in the first place; given this need, however, it is odd to assume that voters will not turn to domestic benchmarking by comparing current economic outcomes to what they have observed in the recent past. To the best of my knowledge, Palmer and Whitten (1999) is the only study that recognizes

3. Hansen, Olsen, and Bech (2015) provide experimental evidence, though from a single case, on the electoral importance of relative international performance. A predictive test of this aspect of relative performance in the context of the 2013 German Bundestag election is presented by Kayser and Leininger (2016). 
the domestic aspect of relative performance by distinguishing between expected and unexpected components of economic outcomes in industrialized democracies. Results of the analyses indicate that the unexpected components of growth and inflation have stronger electoral effects than for their overall levels, yet it is not possible to infer whether voters are rewarding competent incumbents or those who happen to be in power during a global expansion period.

Crucially, no study in the literature offers a unified perspective by considering relative domestic and international performance simultaneously. In their path-breaking work, Kayser and Peress $(2012,681)$ acknowledge that their goal is to establish that voters in advanced democracies engage in cross-national benchmarking, and they leave the question of how much "cross-national benchmarking matter[s] relative to within-country over-time comparisons" open. In addition, they do not offer a theoretical account for why relative performance should matter, and we do not know whether their results would hold in developing democracies as they cover elections from high-income OECD countries only. Campello and Zucco (2016), for example, report that voters in a subset of Latin American countries seem to ignore the impact of exogenous shocks on domestic economies when deciding how to vote. ${ }^{4}$ The authors conjecture that citizens' relatively low levels of access to information in these countries might account for this result, but do not test this proposition.

I develop such a unified theoretical framework as an extension to the competence model of retrospective voting and test its predictions using a large, original data set that covers elections from both developed and developing democracies. A formal derivation of the model is presented in the next section, but the intuition can be stated informally. In this framework voters seek high economic growth, and competent politicians are more likely to deliver it. Yet competence is private information and hence not directly observed, so the challenge for voters is how to select competent politicians. To do this, voters observeeconomic outcomes in the retrospectiveeconomy because if competent politicians are able to deliver higher growth, economic outcomes should provide information about incumbent competence. Thus, voters use economic outcomes to assess incumbent competence, which in turn influences their vote choice.

Accordingly, the task for voters is to interpret economic outcomes to assess incumbent competence. Interpreting economic outcomes is not straightforward, however. There are at

4. Campello and Zucco (2016) focus on 65 elections held between 1980 and 2010 in 10 Latin American countries which they identify as "lowsavings-commodity-exporting" countries. least two challenges associated with linking economic outcomes to incumbent competence, and consideration of economic outcomes relative to recent past outcomes in the country and in a cross-national perspective helps voters to cope with these challenges. First, a given outcome might signal different levels of incumbent competence depending on the domestic context. There are some slow-moving, countryspecific structural factors - for example, human capital, demographic structure, development level—that shape countries' potential economic performance to a significant extent in the short-to-medium term (Barro 1991). For example, a 7\% yearly GDP growth has not been an unusually high growth rate for China in the past two decades, yet it would have been highly unlikely for a developed country like France. By comparing economic outcomes during the current incumbent's term to recent past outcomes in the country, voters can put the incumbent's performance into the proper domestic context. ${ }^{5}$

A second challenge is the presence of economic shocks beyond incumbent control and, hence, competence. An international comparative framework could help voters to distinguish incumbent competence from exogenous shocks to the economy. Here we have to recognize that exogenous shocks typically affect multiple countries simultaneously, especially in the last few decades due to the increased level of economic integration. By observing how the national economy has performed in comparison to other countries that were likely to have been affected by exogenous shocks in a similar fashion, a voter can obtain useful information on how well the incumbent manages the economy, net of the impact of the exogenous shock. If a French voter during tough economic times in France observes economic weakness throughout Europe, she would conclude that there is a negative economic shock affecting the French economy as well. She can then incorporate this information together with how the French economy has performed relative to other European economies into her evaluation of the incumbent's competence.

An important condition for the electoral salience of relative international performance is the availability of relevant information to voters, from both a supply and a demand perspective. Most voters should be able to obtain sufficient information about domestic economic outcomes as a by-product of their daily economic activities and decisions even if they do not follow the news closely (Aidt 2000). The same cannot be said about international economic outcomes, however. Hav-

5. Fixed-effects models may be considered a way of accounting for domestic comparisons, since they pick up within-country variation over time. This approach would not be satisfactory, however, as one would have to make the strict assumption that economic outcomes in each period should be compared with the average level over the entire period of analysis. 
ing a sense of how the domestic economy fares in international comparisons requires receiving and digesting information about other countries' economies, and the media is likely to be the primary source of such information for voters (Kayser and Peress 2012). The adequate availability of such information to a large number of voters should be a necessary condition for the electoral salience of relative international performance.

In addition to the importance of availability of relevant information for international comparisons, my theoretical development suggests that relative international performance is more informative to voters about the incumbent's competence if there is a group of countries (the international reference group) that shows a high degree of business cycle comovement with the voters' country. This is because if the domestic economy is expected to track the reference group outcomes very closely, then the voters can attribute any deviation in the country's performance from the reference group to incumbent competence. Empirical studies in the economics literature suggest that higher trade intensity between countries results in more closely correlated business cycles (e.g., Clark and Van Wincoop 2001; Frankel and Rose 1998). Accordingly, higher trade intensity between the voters' country and the reference group countries should lead voters to put more weight on relative international performance when evaluating the incumbent's competence.

\section{A REFERENCE POINT THEORY OF ECONOMIC VOTING}

My theory is based on the competence model within the selection view of elections (Alesina and Rosenthal 1995; Persson and Tabellini 1990). In this section, I first present the competence model of economic voting in its original form, and then I elaborate on my extension. ${ }^{6}$ Consider an economy characterized by the following Phillips supply curve

$$
g_{t}=\bar{g}+\pi_{t}-\pi_{t}^{e}+\eta_{t},
$$

where $t$ indicates the time period, $g_{t}$ is the rate of economic growth, $\bar{g}$ is the "natural rate of growth" of the country, $\pi_{t}$ is the inflation rate, $\pi_{t}^{e}$ is the expected inflation rate by voters for $t$ at period $t-1$, and $\eta_{t}$ is a random shock to the economy. The random shock $\eta_{t}$ is the sum of two components, $\eta_{t}=c_{t}+\gamma_{t}$, which cannot be observed separately by voters; $c_{t}$ is the competence of the incumbent, and $\gamma_{t}$ is a "nonpolitical" exogenous shock to the economy. The nonpolitical

6. My derivation of the competence model of economic voting draws heavily on the presentation in Alesina and Rosenthal (1995), Duch and Stevenson (2008), and Scheve (2001).

7. The natural rate of growth refers to a case of constant real wages. If the realized inflation exceeds expectation, then the reduction in the real wages implies a higher labor demand and higher growth rate. shock $\gamma_{t}$ represents various exogenous shocks that affect the rate of growth and are beyond government control and competence. It is assumed to be drawn from a normal distribution with zero mean and finite variance $\sigma_{\gamma}^{2}$.

The competence term, $c_{t}$, captures the impact of the incumbent's managerial competence on the economy - a competent incumbent can achieve higher growth for a given level of inflation. Competence is modeled as a random variable since the nature of the policy problems that the incumbent might face is not known ex ante. Although random, an important feature of competence is that it is persistent; an incumbent who is competent today is likely to be competent in the near future as well. This is captured by modeling competence as a first-order moving average MA(1) of a sequence of competence shocks, $c_{t}=\mu_{t}+\mu_{t-1}$, that are drawn from a normal distribution with zero mean and finite variance $\sigma_{\mu}^{2}$.

Voters' preferences regarding inflation and growth are specified as

$$
u\left(\pi_{t}, g_{t}\right)=-\frac{1}{2} \pi_{t}^{2}+b g_{t} .
$$

Thus, voters like higher growth and lower inflation, and $b>$ 0 captures the benefit of growth relative to the cost of higher inflation. They are assumed to observe all economic variables in equation (1), that is, $g_{t}, \bar{g}, \pi_{t}, \pi_{t}^{e}$ (and indirectly $\eta_{t}$ ). Voters are also assumed to learn $\mu_{t}$ in the period following its realization. So at time $t$, voters know $\mu_{t-1}$ but not $\mu_{t}{ }^{8}$ These assumptions imply that there is no room for strategic pre-electoral manipulation - politicians have nothing to gain from doing anything but setting inflation at its expected rate, that is, $\pi_{t}=\pi_{t}^{e}$. This simplifies equation (1) so that the realized growth rate equals natural rate of growth plus competence and exogenous shocks:

$$
g_{t}=\bar{g}+\mu_{t}+\mu_{t-1}+\gamma_{t} .
$$

We assume that there is an election at the end of period $t$, and two candidates (the incumbent and the challenger) compete for unified control of the executive. Given the utility function of the voter in equation (2), she would like to maximize growth in the next period, and the expression of growth in equation (3) implies that her only tool is to select the politician whom she expects is going to be more competent in the next period. Regarding the challenger, the voter does not have any information concerning his or her competence since the competence process is MA(1). Thus,

8. Alesina and Rosenthal (1995) stress that by imposing a one-period delay on the competence shock, they are trying to capture the idea of voters having difficulty in distinguishing between competence and nonpolitical contributions to growth. 
the best forecast of the challenger's competence in period $t+1$ is simply the unconditional mean of competence in the population, zero.

The voter has more information available to forecast the incumbent's competence in period $t+1$. She observes how the economy performed in period $t$, and because of the persistent nature of competence, this information can be used to estimate the expected competence of the incumbent in period $t+1$ if he or she gets reelected. A standard derivation from the literature that is presented in the appendix (available online) results in the following expected value of the incumbent's competence in period $t+1$ :

$$
E\left[c_{t+1}\right]=\frac{\sigma_{\mu}^{2}}{\sigma_{\mu}^{2}+\sigma_{\gamma}^{2}}\left(g_{t}-\bar{g}-\mu_{t-1}\right) .
$$

Equation (4) is the key result of the model as a signal extraction problem. The latter term $\left(g_{t}-\bar{g}-\mu_{t-1}\right)$ indicates how growth in the current period differs from the country's natural level of growth, discounted by the impact of the incumbent's known level of competence in the previous period. Voters also try to estimate how much of the observed economic performance can be attributed to incumbent competence via the first term, $\left(\sigma_{\mu}^{2} /\left(\sigma_{\mu}^{2}+\sigma_{\gamma}^{2}\right)\right)$. This weighting term can be interpreted as the "competence signal" that controls how much information about the competence of the incumbent voters can extract from the observed growth of the economy. If the variance of the competence term $\sigma_{\mu}^{2}$ is large relative to the variance of the nonpolitical component of growth $\sigma_{\gamma}^{2}$, then voters are more prone to believe that any deviation of growth from its natural rate can be attributed to incumbent competence, since it varies more than other possible shocks. The attention of scholars of economic voting has been mostly on the interpretation of how the context affects this competence signal. Duch and Stevenson (2008), for example, argue that higher trade openness and a more extensive state sector imply that $\sigma_{\gamma}^{2}$ is large relative to $\sigma_{\mu}^{2}$ so that we should expect less economic voting in such a context. ${ }^{9}$

\section{AN EXTENSION AND REINTERPRETATION OF THE COMPETENCE MODEL}

There are at least two shortcomings of the competence model in its current form and use in empirical analyses. First, voters

9. Duch and Stevenson $(2008,149-55)$ also contend that voters who are attentive to global economic outcomes can better distinguish the relative sizes of competence and nonpolitical shocks. For example, if a voter is aware that fluctuations in her country's macroeconomy are very similar to those of an external set of countries, she is likely to conclude that the competency shocks should be small relative to nonpolitical shocks. The emphasis here is again on how the context affects the competence signal and not on the relative performance of the incumbent. in the model are assumed to consider national economic outcomes independent of trends in the global economy, as they evaluate the incumbent's performance only against their own country's natural rate of growth via the term $\left(g_{t}-\bar{g}\right)$. Voters therefore are assumed not to make any effort to estimate the value of the exogenous shock, $\gamma_{t}$, to their national economy; it does not matter whether the incumbent's term coincides with a global expansion or recession period or whether the national economy performs better or worse than other countries. This setup ignores relevant information that might be available to voters for the interpretation of economic outcomes. Through a simple extension of the model, I show that voters can better assess the competence of the incumbent by observing their country's relative international performance.

Another issue is related to the application of the model in empirical analyses. One of the key terms in the model is the country's natural rate of growth, $\bar{g}$, which voters take as a (domestic) reference point when evaluating the incumbent's performance. Accordingly, voters do not respond to the absolute level of economic growth in period $t$ but to its deviation from $\bar{g}$. Yet scholars have typically paid scant attention to $\bar{g}$ in empirical analyses, treating it as a country-specific constant. Duch and Stevenson $(2008,2010)$, for example, designate it as a constant, long-term equilibrium component that reflects voters' long-term expectations regarding economic outcomes. I argue that this approach is ill-suited to represent voter behavior. It is more appropriate to interpret $\bar{g}$ as reflecting a dynamic reference point that is shaped by recent domestic trends rather than a constant. In the following, first I present my extension to the competence model that incorporates relative international performance into the voter's estimation; then I discuss this alternative interpretation of $\bar{g}$.

\section{Incorporating relative international performance}

To see how relative international performance helps voters to better assess the incumbent's competence, suppose that there is a group of countries which we label as the "reference group," R. An ideal reference group satisfies two conditions. First, the natural rates of growth of the voter's country and the reference group should be close to each other. That is, in the absence of any shocks, the growth rate of the voter's country is about the same as the average of the reference group countries. Second, the reference group should exhibit a high degree of business cycle comovement with the voter's country. Business cycles refer to the fluctuations in economic activity over time (e.g., change in GDP), and the economies of countries with a high degree of business cycle comovement move more in lockstep. This implies that exogenous shocks affect the economies of the voter's country and the reference group countries in a similar direction and magnitude. The better 
these conditions are met, the more information about the incumbent's competence the voter can obtain by observing her country's economic performance relative to the reference group.

The two conditions regarding the relationship between economic outcomes in the voter's country and the reference group can be formalized as in equations (5) and (6):

$$
\begin{gathered}
\bar{g}=\bar{g}^{R}+\varepsilon \quad \text { where } \varepsilon \sim \mathcal{N}\left(0, \sigma_{\varepsilon}\right) \\
\gamma_{t}, \gamma_{t}^{R} \sim \mathcal{N}\left(0,0, \sigma_{\gamma}^{2}, \sigma_{R}^{2}, \rho\right) .
\end{gathered}
$$

Equation (5) states that the country's natural rate of growth, $\bar{g}$, equals the natural rate of growth of the reference group, $\bar{g}^{R}$, plus a disturbance term, $\varepsilon$. The variance of the disturbance term is a measure of the similarity between the natural growth rates of the country and the reference group. Second, denote $\gamma_{t}^{R}$ as the random exogenous shock to the reference group, drawn from a normal distribution with zero mean and variance $\sigma_{R}^{2}$. Then equation (6) states that $\gamma_{t}^{R}$ and the exogenous shock to the voter's country, $\gamma_{t}$, have a bivariate normal distribution with zero means, variances of $\sigma_{R}^{2}$ and $\sigma_{\gamma}^{2}$, and a correlation coefficient of $\rho$.

Both $\rho$ and the relationship between $\sigma_{R}^{2}$ and $\sigma_{\gamma}^{2}$ have independent effects on the degree of business cycle comovement between the voter's country and the reference group. The correlation $\rho$ serves as a measure of the synchronicity of the business cycles - whether the timing and direction of exogenous shocks coincide. This measure alone is not sufficient to specify business cycle comovement, however, because there could be cross-country differences with respect to the magnitude of the shocks, that is, the amplitude of the cycles (Mink, Jacobs, and de Haan 2007). Even if the correlation $\rho$ is one, the voter's country and the reference group could experience fluctuations of divergent magnitudes if the variances $\sigma_{R}^{2}$ and $\sigma_{\gamma}^{2}$ are different. In order to specify the degree of business cycle comovement between the voter's country and the reference group with a single parameter in the model, I assume that $\sigma_{R}^{2}$ and $\sigma_{\gamma}^{2}$ are approximately equal to each other, $\sigma_{R}^{2} \approx \sigma_{\gamma}^{2}$.

How does this framework help the voter to estimate the incumbent's competence? Recall that in the original model the voter faced a signal extraction problem because she could not observe the competence and exogenous shocks separately. Thus, if the voter can obtain some information to estimate $\gamma_{t}$, she can avoid the signal extraction task and form an expectation of $\mu_{t}$ directly. By observing growth in the reference group, the voter can estimate $\gamma_{t}^{R}$, which in turn can be used to estimate $\gamma_{t}$ given that $\gamma_{t}^{R}$ and $\gamma_{t}$ are correlated.

The expression of growth for the voter's country in equation (3) can be adopted to write the growth equation for the reference group, as in equation (7), with each term corresponding to the average of the reference group countries (denoted with superscript $R$ ).

$$
g_{t}^{R}=\bar{g}^{R}+\mu_{t}^{R}+\mu_{t-1}^{R}+\gamma_{t}^{R} .
$$

A critical observation and a corresponding assumption at this point is regarding the values of the competence shocks for the reference group, $\mu_{t}^{R}$ and $\mu_{t-1}^{R}$. If there are a moderately large number of countries in the reference group, then it is plausible to assume that the average competence shock for the group for a given year is equal to its unconditional expected value, that is, zero. A single country might experience a positive or negative competence shock at any given time, but there should be no reason to assume that the average competence shock across a number of countries is different from its expected value. Within a given group, while some countries would experience positive competence shocks, others would have negative ones; thus, on average, they should cancel out. With this assumption we obtain

$$
\gamma_{t}^{R}=g_{t}^{R}-\bar{g}^{R} .
$$

Accordingly, the voter will attribute any deviation of the observed growth of the reference group from its natural growth rate to the exogenous shock in period $t$. From the voter's point of view, the advantage of observing economic outcomes in the reference group is that the effects of competence shocks are purged. In addition, although voters might not directly observe the natural growth rate of the reference group, $\bar{g}^{R}$, equation (5) indicates that their best estimate for it is simply their own country's natural rate of growth. Thus, voters can estimate $\gamma_{t}^{R}$ through the following equation:

$$
\gamma_{t}^{R}=g_{t}^{R}-\bar{g} .
$$

Now that the voter estimates $\gamma_{t}^{R}$ through equation (9), she can form an estimate for $\gamma_{t}$ as well:

$$
\begin{aligned}
E\left[\gamma_{t} \mid \gamma_{t}^{R}\right] & =\rho \frac{\gamma_{t}^{R}-E\left[\gamma_{t}^{R}\right]}{\sigma_{R}} \sigma_{\gamma}+E\left[\gamma_{t}\right] \\
& =\left(\rho \frac{\sigma_{\gamma}}{\sigma_{R}}\right) \gamma_{t}^{R} \approx \rho \gamma_{t}^{R}
\end{aligned}
$$

because $E\left[\gamma_{t}^{R}\right]=E\left[\gamma_{t}\right]=0$ and the assumption that $\sigma_{R}^{2} \approx \sigma_{\gamma}^{2}$. Using this expected value for $\gamma_{t}$, voters' optimal forecast for the incumbent's competence in period $t+1$ will be

$$
\begin{aligned}
E\left[c_{t+1}\right] & =E\left[\mu_{t} \mid g_{t}, \gamma_{t}^{R}\right] \\
& =E\left[g_{t}-\bar{g}-\mu_{t-1}-\gamma_{t} \mid \gamma_{t}^{R}\right] \\
& =g_{t}-\bar{g}-\mu_{t-1}-\rho \gamma_{t}^{R} \\
& =g_{t}-\bar{g}-\mu_{t-1}-\rho\left(g_{t}^{R}-\bar{g}\right) \\
& =(1-\rho)\left(g_{t}-\bar{g}\right)+\rho\left(g_{t}-g_{t}^{R}\right)-\mu_{t-1} .
\end{aligned}
$$


Equation (11) is the key result of my extension. The terms in this expression that link economic outcomes to incumbent competence are $g_{t}, \bar{g}$, and $g_{t}^{R}$, as $\mu_{t-1}$ just discounts the impact of the competence shock in the previous period. In order to estimate the incumbent's competence, the voter compares growth in the current period (i) to the country's natural rate of growth $\left(g_{t}-\bar{g}\right)$ and (ii) to the growth of the reference group countries $\left(g_{t}-g_{t}^{R}\right)$. Essentially, then, the voter uses two reference points to evaluate the incumbent's performance. One of the reference points is domestic and the other is international. The voter assigns a higher level of competence to incumbents who perform better relative to these reference points, regardless of the absolute level of performance.

We also see that the domestic and international performance components in equation (11) are weighted by $(1-\rho)$ and $(\rho)$, respectively, where $\rho$ is the correlation between the exogenous shocks to the voter's country and to the reference group. These weights indicate how the voter combines domestic and international performance to calculate the incumbent's expected competence in a very intuitive way. When $\rho$ is small, meaning a low degree of business cycle comovement between the voter's country and the reference group, the voter will put little weight on relative international performance. In this case, the voter's competence calculation will be dominated by relative domestic performance. Conversely, when $\rho$ is closer to one, relative international performance will be given more weight than domestic.

\section{A reinterpretation of the domestic reference point in the model}

An important term both in the competence model in its original form and in my extension is $\bar{g}$, the country's natural rate of growth. This term serves as a domestic reference point for voters, and theoretically it refers to the growth rate that the national economy would attain if it were isolated from inflationary (or policy), competence, and exogenous shocks. Although quite intuitive theoretically, it is much less clear how to operationalize this term in empirical analyses. Other terms in the model (i.e., the growth rates of the country and of the reference group in a particular period) have relatively clear measures, but what would correspond to a country's natural rate of growth that is both theoretically appropriate and feasible to observe from voters' perspective? Addressing this question is important, as the misspecification of the reference point would lead to invalid conclusions in empirical analyses.

As I noted before, the practice in the literature is to consider this term to be a country-specific fixed effect reflecting a constant, long-term equilibrium component (e.g., Duch and
Stevenson 2008, 2010). This approach has significant shortcomings, however. Theoretically, a country's natural rate of growth could change over time (e.g., due to structural changes in human capital, productivity, etc.), and treating it as a longterm constant would miss such dynamics. In addition, this assumption places a considerable cognitive burden on voters, because a country-specific fixed effects approach implies that voters compare the incumbent's performance to economic outcomes over the entire period of analysis, typically corresponding to a period of 20-40 years. Indeed, considering the natural rate of growth of a country as a long-term factor that is known by voters constitutes an intriguing paradox for approaches that at the same time use only election-year measures of economic performance, claiming that voters forget most of their previous experience, and thus are myopic.

It is more appropriate to characterize $\bar{g}$ as a dynamic reference point that voters continuously update in line with their most recent experience. In particular, voters could use economic outcomes during the previous term as a domestic benchmark to evaluate the incumbent's performance in the current term. By definition, voters' search for a domestic reference point should exclude the current term, and thus this search might be dominated by outcomes during the previous term, potentially the most cognitively available information for this purpose. Outcomes during the previous term were affected by competence and exogenous shocks as well, however, and therefore this substitution would not exactly correspond to the country's natural rate of growth as theoretically conceived. Still, this approach might be considered as a middle ground for empirical analyses, reflecting rational voters' efforts to evaluate the incumbent's performance in a proper domestic context while at the same time acknowledging voters' cognitive and informational limitations.

This theoretical framework generates the following observable implications, which I explore in the rest of the article. First, equation (11) directly points to the importance of relative performance for incumbent support.

H1. Incumbents who have presided over relatively better (worse) economic outcomes, in light of domestic and international comparisons, should be rewarded (punished) at the polls. Once we account for relative performance, absolute measures of performance (e.g., election-year growth) should have no effect on incumbent vote share.

Second, the presence of the term $g_{t}^{R}$, the growth rate of the reference group countries, in equation (11) indicates that voters need to have some knowledge of international economic 
outcomes in order to judge their countries' relative international performance.

H2. The availability of information about international economic outcomes is a necessary condition for the electoral importance of relative international performance.

Finally, the weighting of the domestic and international performance components by $\rho$ predicts that the country's international trade intensity is a moderating factor for the relationship between relative international performance and incumbent support.

H3. The electoral importance of relative international performance is positively correlated with the country's trade intensity.

\section{RELATIVE ECONOMIC PERFORMANCE AND ELECTIONS}

Does relative performance have electoral consequences for incumbents? In this section, I explore the electoral effects of relative economic performance systematically and test the three hypotheses derived from my theory by analyzing an original cross-national data set on economic voting that incorporates measures of relative domestic and international performance.

\section{Data and measures}

My data set comprises 475 presidential and legislative elections in 62 countries over a period of 40 years, from 1965 to 2014. This sample covers countries with a population of 1 million or more that received a democracy rating (polity2) of +6 or better in the Polity IV data set at the time of a presidential or legislative election, excluding postcommunist countries. ${ }^{10}$ Elections from postcommunist countries are excluded because of the persuasive evidence in the literature that economic voting has a different dynamic in these countries. The transition away from communism was a period of extraordinary economic turbulence with long-lasting effects in voting behavior. In particular, the "winners" and "losers" of the transition continued to vote according to parties' stance vis-à-vis the communist past and the reform period (Fidrmuc 2000; Pop-Eleches and Tucker 2011; Tucker 2006). Tucker

10. In addition, a number of cases are missing due to other factors, which include opposition party boycotts, noncompetitive institutional agreements between parties, or inability to identify the incumbent party or candidate. The list of elections in the data set and information on missing cases are provided in the appendix.
(2006), for example, shows that voters in postcommunist countries reward protransition parties as the economy improves even if they are not in power. Empirical evidence indicates that such a "transitional identity" model better explains electoral outcomes in postcommunist countries than the standard accounts of economic voting.

The dependent variable in the analyses is the vote share of the party of the chief executive (Incumbent Vote).${ }^{11}$ Even in coalition governments, the party of the prime minister gets the most credit or blame for economic outcomes (Duch and Stevenson 2008; van der Brug, van der Eijk, and Franklin 2007); therefore, focusing on the vote share of the chief executive's party has been the standard practice in the literature (e.g., Duch and Stevenson 2008; Hellwig and Samuels 2007; Kayser and Peress 2012). To control for past election outcomes, I include the party's vote share in the previous election into the specifications as well (Previous Vote). ${ }^{12}$

The key independent variables in the analyses are measures of relative domestic and international economic performance. My measure of relative domestic economic performance is the difference in average annual real GDP growth between the current incumbent's term and the previous term. ${ }^{13}$ This measure is illustrated in figure 1. Suppose we are at the time of Election $t_{t+1}$ and the voter evaluates the relative domestic performance of the incumbent. According to my measure, she would compare the average growth during the incumbent's term (from Election ${ }_{t}$ to Election $_{t+1}$, namely, Growth $_{\text {Current }}$ ) with the average growth during the previous term (from Election ${ }_{t-1}$ to Election $t$, namely, Growth Previous $_{\text {. The }}$. The difference between these average growth rates gives Relative Domestic Growth. For example, if the average growth during the incumbent's term is $4 \%$, and the average growth in the previous term is 3\%, then Relative Domestic Growth takes the value of $1 \%$.

11. Chief executive corresponds to prime minister in parliamentary democracies and to president in presidential and semi-presidential democracies; hence legislative elections in the latter types of democracies are not included in the analyses. I use electoral results from the first round of elections for multiround elections.

12. Comparing the chief executive's vote share across two elections requires both elections to be democratic (i.e., the country having polity 2 score of +6 or better), thus for countries that have democratized during the period of analysis the initial election after democratization is not included in the data set.

13. Following Hellwig and Samuels (2007), I use economic data from the year preceding the election if the election was held in the first six months of the year. For example, if the election is held in February 1990, the year 1990 is not considered as part of the incumbent's term. Economic data of 2014 were not available for many countries as of the writing of the article; therefore, elections held in the second half of 2014 are excluded from the analysis. 


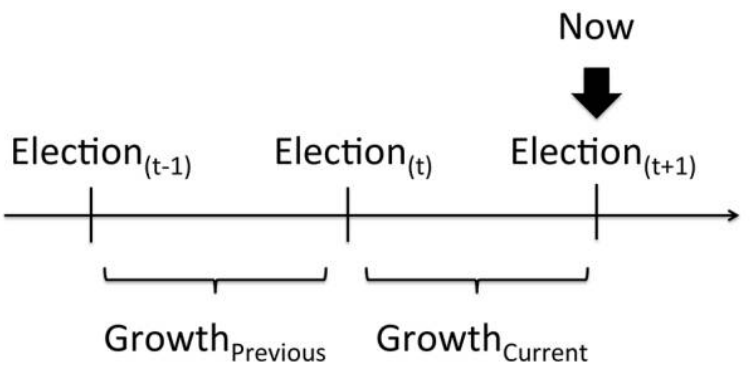

Relative Domestic
Growth

Figure 1. Construction of Relative Domestic Growth

My focus on the economic outcomes during the incumbent's whole term is a point of divergence from the traditional economic voting literature. The dominant practice in macro-level studies is to use only the election-year economic outcomes (or even a shorter period preceding the election) as the economic explanatory variables, because "voters ... reward incumbents not broadly for economic growth throughout incumbents' terms, but narrowly for conditions in the six months or year before Election Day" (Healy and Lenz 2014, 31). From a theoretical point of view this approach would not be appropriate for my argument - if economic outcomes are relevant for voting decisions to the extent that they provide information on the incumbent's competence, considering the whole term rather than the election year should be more informative. Moreover, all the evidence pointing to the dominance of election-year economic conditions comes from the US presidential elections (e.g., Achen and Bartels 2004; Kiewiet 1983; Kramer 1971), and we do not know whether this pattern is generalizable to other democracies. In any case, in my models I control for the election-year growth in real GDP (Election-Year Growth) to test whether it will still have an impact on incumbent vote share after accounting for my measures of relative economic performance.

The second key independent variable in my model is a measure of relative international economic performance. To construct this measure, I took one of the approaches in Kayser and Peress (2012) and identified the top five export markets for each country and election year. The international reference point for a given country, International Growth, is the weighted average growth rate of its five export markets during the incumbent's term, where weights are given by the proportion of exports sent to each market. Accordingly, the top export market of a given country will have the biggest effect on that country's reference point, followed by other export markets. The difference between the average growth of a country during the incumbent's term and this trade-weighted reference point gives my measure of relative international performance, Relative International Growth. ${ }^{14}$

Models include a set of controls commonly used in the literature. I control for the presence of coalition governments in parliamentary democracies (Coalition) as it should be negatively associated with vote shares of all parties, including that of the executive's party. The effective number of parties (Eff. Num. of Parties) in a country should have a similar effect. As the data set includes both legislative and presidential elections, I include a dummy variable for the latter (Presidential). Finally, Reelection is a dummy variable indicating that the incumbent president is running for reelection in presidential and semi-presidential systems. As Hellwig and Samuels (2007) note, the advantages associated with recognition and organization for sitting incumbents predict a positive coefficient for this variable. ${ }^{15}$

\section{Analysis and results}

Following the general approach in the literature (e.g., Bartels 2014; Hellwig and Samuels 2007; Kayser and Peress 2012) I estimate my models with ordinary least squares (OLS) regression using Huber-White robust standard errors clustered by country. Table 1 presents results for all samples. In model (1), I consider a traditional model of economic voting with election-year growth as the key independent variable. We see that growth in the election year has a positive effect on incumbent vote share, a result in line with the existing literature.

Model (2) introduces my measures of relative performance, Relative Domestic Growth and Relative International Growth. Both variables have positive and statistically significant effects on the incumbent's vote, providing evidence for the hypothesis that voters reward (punish) incumbents on whose watch the economy performs relatively better (worse) in domestic and international comparisons. This result holds even after controlling for growth in the election year, and crucially, election-year growth ceases to be a predictor for incumbent support once we account for relative performance. Thus hypothesis 1 , that economic voting is driven by the incumbents' relative performance, finds empirical support. Substantively, the analysis indicates that one-percentage-point

14. As Kayser and Peress (2012) note, countries that are close to each other, have large economies, share a common border, are members of the same region, speak the same language, and engage in regional free trade agreements trade more intensively. All these factors should be positively correlated with media coverage, and thus voters should be more likely to be exposed to information in the media about the economic outcomes in countries with closer trade linkages than others.

15. Data sources for all variables are listed in the appendix. 
Table 1. The Impact of Relative Economic Performance on Incumbent Vote

\begin{tabular}{lccccc}
\hline & \multicolumn{2}{c}{$(1)$} & & \multicolumn{2}{c}{$(2)$} \\
\cline { 2 - 3 } \cline { 5 - 6 } DV: Incumbent Vote & Coefficient & SE & Coefficient & SE \\
\hline & & & & \\
Relative Domestic & & & & \\
$\quad$ Growth & & & $.574^{* * *}$ & $(.204)$ \\
Relative International & & & & \\
$\quad$ Growth & & & $.719^{* *}$ & $(.276)$ \\
International Growth & & & .298 & $(.349)$ \\
Election-Year Growth & $.676^{* * *}$ & $(.163)$ & .216 & $(.143)$ \\
Previous Vote & $.689^{* * *}$ & $(.064)$ & $.679^{* * *}$ & $(.063)$ \\
Coalition & .216 & $(1.039)$ & .129 & $(1.015)$ \\
Eff. Num. of Parties & $-1.435^{* * *}$ & $(.366)$ & $-1.536^{* * *}$ & $(.381)$ \\
Presidential & $-4.558^{* * *}$ & $(1.109)$ & $-4.820^{* * *}$ & $(1.103)$ \\
Reelection & $12.284^{* * *}$ & $(2.481)$ & $12.661^{* * *}$ & $(2.393)$ \\
Constant & $11.692^{* * *}$ & $(3.249)$ & $13.040^{* * *}$ & $(3.405)$ \\
$\quad$ Observations & 460 & & 460 & \\
$\quad R^{2}$ & .584 & & .608 &
\end{tabular}

Note. OLS estimates with robust standard errors clustered by country in parentheses.

${ }^{*} p<.10$.

${ }^{* *} p<.05$.

${ }^{* * *} p<.01$.

increase in relative domestic as well as international growth is associated with about a 1.3 percentage point increase in incumbent vote share.

Model (2) highlights that while the recent approaches in the literature that take relative international performance into account to explain economic voting are heading in the right direction, they are incomplete. Similarly, we have to consider relative domestic performance, as voters engage in domestic benchmarking as well. Here I considered one particular theoretically guided measure of domestic benchmarking (the difference in average growth between the current and previous terms), but the question of how voters take into account previous economic outcomes when evaluating the present could be further pursued. For example, in table A2 of the appendix I consider the possibility of voters only looking at the election year relative to the previous year, which fails to explain support for the incumbent. Thus, a comparison of economic outcomes across different incumbency terms turns out to be more electorally relevant than year-to-year comparisons, an observation in line with the idea of voters trying to gauge incumbent competence by observing economic outcomes.

A second hypothesis that I put forward is the availability of information about the international economy as a condition for the electoral salience of relative international performance. My large sample includes elections from a diverse set of developed and developing countries, which facilitates exploration of this hypothesis. One plausible proxy for the availability of information is the population's average level of schooling. In countries where the average voter is better educated, there could be more demand and supply for such information in the media. Surveys in the United States indicate that a higher level of education is associated with greater levels of news consumption. ${ }^{16}$ In addition, it might be appropriate to conceptualize the availability of information to voters not just as the amount of exposure to news but also as voters' capacity to "receive" information in terms of comprehension and retention (Price and Zaller 1993). There is evidence in the literature that education is positively correlated with recall of current news and ability to digest information in news stories (e.g., Jerit, Barabas, and Bolsen 2006; Price and Zaller 1993). Thus, a higher level of education should make it easier for a voter to judge her country's relative international performance, considering both exposure to relevant information and the ability to process it.

In order to test this hypothesis, in model (1) of table 2 I add the interactions of the adult population's average years of total schooling in a country (Avg. Schooling) with economic performance measures. ${ }^{17}$ The coefficient of the interaction of Avg. Schooling with Relative International Growth is positive and statistically significant, indicating that a better educated population is a strengthening factor for the electoral importance of relative international performance. Figure 2 plots the conditional coefficient of Relative International Growth produced by Model (1) across the sample range of Avg. Schooling. The marginal effect of relative international growth on incumbent vote increases with the population's average years of schooling and becomes statistically significant only when a certain threshold is passed. In the specification that I employ, relative international growth has a positive and statistically significant effect on incumbent vote when voters have at least about eight years of schooling on average.

This analysis suggests that, considering the average years of schooling across countries in the last decade, relative international performance will be a relevant factor for the electoral fortunes of incumbent governments in advanced democracies like Germany, the Netherlands, and Australia, but not in developing democracies like Brazil, Colombia, India, or Turkey. Thus, incumbents in developing democracies are

16. See, e.g., Dalager (1996) and reports by Pew Research (http:// pewrsr.ch/X0QIAU) and the American Press Institute (http://disq.us/8t3j22).

17. Data on schooling are from Barro and Lee (2010). 
Table 2. Average Schooling, Income, Trade Intensity, and Relative Economic Performance

(1)

\begin{tabular}{|c|c|c|c|c|c|c|c|c|}
\hline \multirow[b]{2}{*}{ DV: Incumbent Vote } & & & & \\
\hline & Coefficient & SE & Coefficient & SE & Coefficient & SE & Coefficient & SE \\
\hline Rel. Intl. Growth & -.518 & $(.806)$ & -.053 & $(1.497)$ & .835 & $(1.379)$ & -.530 & $(.796)$ \\
\hline$\times$ Avg. Schooling & $.157^{\star}$ & $(.091)$ & & & & & $.159^{\star}$ & $(.090)$ \\
\hline$\times$ Income & & & .094 & $(.157)$ & & & & \\
\hline$\times$ Trade Intensity & & & & & .009 & $(.255)$ & & \\
\hline Rel. Dom. Growth & $.999^{*}$ & $(.593)$ & 2.287 & $(1.485)$ & $1.971^{\star *}$ & $(.857)$ & $1.129^{\star}$ & $(.588)$ \\
\hline$\times$ Avg. Schooling & -.051 & $(.074)$ & & & & & -.065 & $(.073)$ \\
\hline$\times$ Income & & & -.191 & $(.157)$ & & & & \\
\hline$\times$ Trade Intensity & & & & & $.261^{\star}$ & $(.148)$ & & \\
\hline Election-Year Growth & .701 & $(.570)$ & 1.800 & $(1.104)$ & -.304 & $(.669)$ & .882 & $(.576)$ \\
\hline$\times$ Avg. Schooling & -.062 & $(.070)$ & & & & & -.079 & $(.071)$ \\
\hline$\times$ Income & & & -.173 & $(.121)$ & & & & \\
\hline$\times$ Trade Intensity & & & & & -.094 & $(.122)$ & & \\
\hline Intl. Growth & .348 & $(.364)$ & .432 & $(.346)$ & .337 & $(.352)$ & .307 & $(.366)$ \\
\hline Previous Vote & $.679^{* * *}$ & $(.063)$ & $.687^{\star * *}$ & $(.063)$ & $.686^{* * *}$ & $(.064)$ & $.683^{\star * *}$ & $(.063)$ \\
\hline Coalition & -.050 & $(1.047)$ & .018 & $(1.055)$ & -.102 & $(1.001)$ & -.144 & $(1.044)$ \\
\hline Eff. Num. of Parties & $-1.597^{* * *}$ & $(.386)$ & $-1.543^{* * *}$ & $(.372)$ & $-1.588^{\star * *}$ & $(.365)$ & $-1.625^{\star \star \star}$ & $(.374)$ \\
\hline Presidential & $-4.658^{\star * *}$ & (1.129) & $-4.072^{\star * *}$ & $(1.144)$ & $-4.338^{\star * *}$ & $(1.203)$ & $-4.294^{\star * *}$ & $(1.116)$ \\
\hline Reelection & $12.168^{\star * *}$ & $(2.440)$ & $12.079^{* * *}$ & $(2.340)$ & $12.280^{* * *}$ & $(2.394)$ & $11.828^{* * *}$ & $(2.484)$ \\
\hline Avg. Schooling & .272 & $(.212)$ & & & & & .283 & $(.267)$ \\
\hline Income & & & $1.064^{\star \star}$ & $(.470)$ & & & -.128 & $(.621)$ \\
\hline Trade Intensity & & & & & .895 & $(.536)$ & .619 & $(.612)$ \\
\hline Constant & $11.044^{\star *}$ & $(4.133)$ & 2.172 & $(5.626)$ & $17.505^{\star * *}$ & $(3.884)$ & $15.110^{*}$ & $(7.731)$ \\
\hline Observations & 45 & & & & 45 & & 45 & \\
\hline$R^{2}$ & .61 & & & & .6 & & .6 & \\
\hline
\end{tabular}

Note. OLS estimates with robust standard errors clustered by country in parentheses.

$* p<10$.

${ }^{* *} p<.05$.

$* * * p<01$.

more likely to ride the wave of a global economic boom or get punished due to domestic fallout of a global recession. My theory and empirical evidence provide a clue for the divergent results reported on cross-national benchmarking in studies focusing on advanced democracies (Kayser and Peress 2012) and developing democracies (Campello and Zucco 2016).

Among other potential proxies for the availability of information about international economic outcomes are the country's average level of income and trade intensity. A higher level of average income could be associated with higher levels of media penetration, and there could be relatively more news about the international economy in the media of countries with higher trade intensity. To probe these possibilities, models (2) and (3) in table 2 consider the interactions of the country's GDP per capita (in constant 2005 US dollars, Income) and trade intensity (Trade Intensity) with eco- nomic performance measures, respectively. ${ }^{18}$ The coefficients of these interaction variables with Relative International Growth are statistically insignificant; thus a country's average level of income and trade intensity do not seem to have an impact on the electoral salience of relative international performance. Model (4) highlights that the average years of schooling has a robust, positive effect on the electoral impor-

18. I construct the trade intensity variable for each country as follows. To measure the bilateral trade intensity between two countries, I calculate the sum of each country's imports from the other divided by the sum of their GDPs (this is the approach taken in Frankel and Rose [1998]). For a given country, I calculate this measure for each of the country's top five export markets in each election year (since the international reference group is defined as the top five export markets). The trade intensity variable for a given country-election is the weighted average of these five bilateral trade intensities. In the analysis I use the natural logarithms of the income and trade intensity variables given their skewed distribution. 


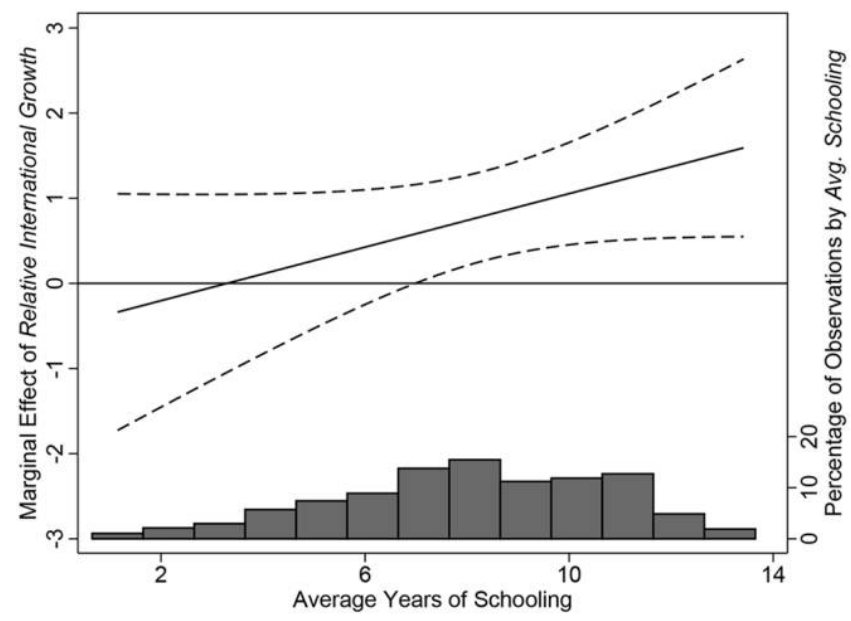

Figure 2. Marginal effect of relative international growth on incumbent vote for different values of schooling. Dashed lines display 95\% confidence intervals around the coefficients calculated from conditional standard errors.

tance of relative international performance even after controlling for income and trade intensity.

Finally, my third hypothesis predicts that the importance of relative international performance for the incumbent's vote share in a country should be positively correlated with the country's trade intensity. The analysis reported in model (3) of table 2 is not appropriate to test this hypothesis, as it includes many countries with low levels of schoolingcontexts where we would not expect relative international performance to be electorally salient due to unavailability of relevant information to voters. Thus, for a proper analysis of the relationship between relative international performance and trade intensity, in table 3 I consider only the elections from countries with at least eight years of average schooling at the time of the election - the empirical threshold derived from previous analyses for the condition of the availability of information. We see that trade intensity of a country does have a positive impact on the electoral salience of relative international performance-figure 3 plots the marginal effect of Relative International Growth for the sample range of Trade Intensity as derived from table 3. Relative international growth does not have a statistically significant effect on incumbent vote share in countries with very low levels of trade intensity even if the country has a highly educated population, though the number of such cases is fairly low.

The preceding analyses of democratic elections during the last 40 years provide support for the three hypotheses derived from the reference point theory of economic voting. Incumbents' relative performance, both domestic and international, significantly affects their electoral fortunes. This finding is robust to the consideration of election-year per- formance; in fact, election-year growth does not predict incumbent vote once we account for incumbents' relative performance during their term. However, the electoral effects of relative international performance depend on the availability of relevant information to voters; my analyses suggest that cross-national benchmarking is limited to democracies with highly educated populations. Finally, deviations from the international benchmark are more informative about the incumbent's competence in countries with higher trade intensity, and therefore the electoral effects of relative international performance should be stronger in such countries; data support this prediction as well.

\section{CONCLUSION}

I began this article with some intriguing anecdotes of politicians appealing to the electorate by highlighting the relative performance of the national economy through comparisons. These anecdotes were puzzling in light of traditional approaches to economic voting, and they hinted at a new perspective on how voters evaluate economic outcomes. Building on this observation, I argued that the relationship between the economy and election results cannot be properly understood without a domestically and internationally comparative framework. I proposed a reference point theory of economic voting

Table 3. Trade Intensity and Relative Economic Performance

\begin{tabular}{lcr}
\hline DV: Incumbent Vote & Coefficient & \multicolumn{1}{c}{ SE } \\
\hline & & \\
Relative International Growth & $4.038^{\star}$ & $(1.894)$ \\
$\quad \times$ Trade Intensity & $.629^{\star}$ & $(.339)$ \\
Relative Domestic Growth & $2.080^{\star}$ & $(1.159)$ \\
$\quad \times$ Trade Intensity & .327 & $(.218)$ \\
Election-Year Growth & -.668 & $(1.086)$ \\
$\quad \times$ Trade Intensity & -.218 & $(.213)$ \\
International Growth & .358 & $(.352)$ \\
Previous Vote & $.680^{* * *}$ & $(.086)$ \\
Coalition & .385 & $(1.117)$ \\
Eff. Num. of Parties & $-1.658^{* * *}$ & $(.529)$ \\
Presidential & $-3.647^{* *}$ & $(1.413)$ \\
Reelection & $7.002^{* *}$ & $(2.720)$ \\
Trade Intensity & 1.184 & $(.690)$ \\
Constant & $18.589^{* * *}$ & $(4.881)$ \\
$\quad$ Observations & 242 & \\
$R^{2}$ & .705 &
\end{tabular}

Note. The analysis includes only elections from countries with at least eight years of average schooling at the time of election. OLS estimates with robust standard errors clustered by country in parentheses.

${ }^{*} p<10$.

${ }^{* *} p<.05$.

${ }^{* * *} p<.01$. 


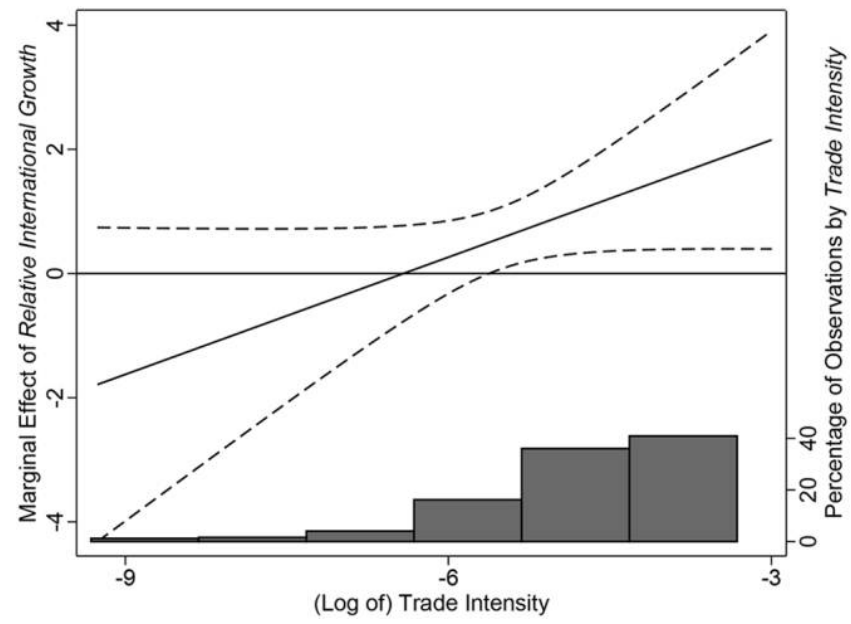

Figure 3. Marginal effect of relative international growth on incumbent vote for different values of trade intensity. Dashed lines display $95 \%$ confidence intervals around the coefficients calculated from conditional standard errors. The analysis includes only elections from countries with at least eight years of average schooling at the time of the election $(N=242)$.

that explicitly incorporated this idea and found support for its macro-level empirical implications using a large, original data set.

The simultaneous recognition of the domestic and international components of an incumbent's relative performance is a theoretical innovation with implications for the study of retrospective voting in general. The domestic aspect of this framework stresses that in order to predict voters' responses to economic outcomes, it is essential to take into account recent past outcomes they have experienced. Voters with divergent past experiences would respond differently to a given economic outcome. For example, the theory predicts that the electoral implications of a given growth rate during the incumbent's term would depend on whether the economy had already been growing by about that rate before the incumbent took office or whether the rate of growth had been much lower or higher. ${ }^{19}$

The international aspect of relative performance highlights a rather recent phenomenon that is likely to be increasingly relevant for election results. Voters progressively become more informed about the state of other countries' economies, and this information furnishes them with an additional standard to evaluate the incumbent's record. My research suggests that currently we observe the electoral effects of relative international performance only in countries with highly educated electorates. This is likely due to the fact that the average voter in such democracies is sufficiently exposed

19. This approach can be applied to policy domains other than the economy; voters' expectations of good or poor performance in any policy domain and their electoral response to the incumbent's record will be shaped by their recent past experiences. to information about global economic outcomes, but the exact mechanism warrants further research. We can expect the electoral relevance of international performance to continue to strengthen, in both developed and developing countries, because of the increased information flow as a result of globalization. Scholars have explored the electoral consequences of globalization by focusing on the integration of national markets for goods and capital (e.g., Duch and Stevenson 2008; Hellwig and Samuels 2007; Scheve 2001). My work highlights the transnational flow of information as another avenue of research to study the electoral impact of globalization.

The analyses presented can be seen as the beginning of a broader research agenda. One of the most exciting research avenues is the exploration of the mechanisms through which voters' reference points for evaluating economic outcomes are shaped. Carefully designed surveys could tap into voters' perceptions of past outcomes in their country and how they shape their current expectations of what good or bad performance would correspond to. These expectations could be affected by the presence of externally imposed economic constraints (e.g., by the IMF, EU) as well. There might also be heterogeneity within the electorate; some voters might pay more attention to inflation than growth or unemployment. Similarly, the question of how voters integrate international economic outcomes into their evaluations is another area of further study. The news media is likely to be the primary source of information for voters about economic outcomes in other countries; thus a plausible starting point in this direction would be a systematic cross-national analysis of how the media reports international economic outcomes.

Overall, I have provided evidence for the presence of electoral accountability through the economic vote-voters are responsive to their representatives' performance in office, and it is possible to observe this with a careful consideration of how they evaluate outcomes. This is a rather encouraging conclusion for democratic theory. Relative performance matters when we look for electoral accountability through the economic vote, and differences in relative performance might account for why electoral rewards (and punishments) can vary for similar absolute levels of economic performance across countries and time periods.

\section{ACKNOWLEDGMENTS}

I am grateful to Susan Stokes, Kenneth Scheve, Thad Dunning, Tariq Thachil, Nikolay Marinov, and Luis Schiumerini for their comments and advice. I also thank the editor and three anonymous reviewers for their valuable feedback, and Simge And 1 and Fatih Erol for research assistance. Earlier versions of the article were presented at Yale University, Koç 
University, University of Mannheim, and at meetings of the Midwest Political Science Association; I thank participants in these seminars as well.

\section{REFERENCES}

Achen, Christopher H., and Larry M. Bartels. 2004. "Musical Chairs: Pocketbook Voting and the Limits of Democratic Accountability." Unpublished manuscript, Princeton University. http://www.princeton.edu / bartels/chairs.pdf.

Aidt, Toke S. 2000. "Economic Voting and Information." Electoral Studies 19 (2): 349-62.

Alesina, Alberto, and Howard Rosenthal. 1995. Partisan Politics, Divided Government and the Economy. New York: Cambridge University Press.

Barro, Robert J. 1991. "Economic Growth in a Cross Section of Countries." Quarterly Journal of Economics 106 (2): 407-43.

Barro, Robert J., and Jong-Wha Lee. 2013. "A New Data Set of Educational Attainment in the World, 1950-2010." Journal of Development Economics 104:184-98.

Bartels, Larry M. 2014. "Ideology and Retrospection in Electoral Responses to the Great Recession.” In Nancy Bermeo and Larry M. Bartels, eds., Mass Politics in Tough Times: Opinions, Votes, and Protest in the Great Recession. New York: Oxford University Press, 185-223.

Campello, Daniela, and Cesar Zucco. 2016. "Presidential Success and the World Economy." Lournal of Politics 78 (2): 589-602.

Clark, Todd, and E. Eric Van Wincoop. 2001. "Borders and Business Cycles." Lournal of International Economics 55 (1): 59-85.

Dalager, Jon K. 1996. "Voters, Issues, and Elections: Are the Candidates' Messages Getting Through?” Journal of Politics 58 (2): 486-515.

Duch, Raymond, and Randolph T. Stevenson. 2008. The Economic Vote: How Political and Economic Institutions Condition Election Results. New York: Cambridge University Press.

Duch, Raymond, and Randy Stevenson. 2010. "The Global Economy, Competency, and the Economic Vote." Lournal of Politics 72 (1): 105-23.

Fidrmuc, Jan. 2000. "Economics of Voting in Post-communist Countries." Electoral Studies 19 (2): 199-217.

Frankel, Jeffrey A., and Andrew K. Rose. 1998. "The Endogenity of the Optimum Currency Area Criteria." Economic Journal 108 (449): 1009-25.

Hansen, Kasper M., Asmus L. Olsen, and Mickael Bech. 2015. "CrossNational Yardstick Comparisons: A Choice Experiment on a Forgotten Voter Heuristic." Political Behavior 37 (4): 767-89.

Healy, Andrew, and Gabriel S. Lenz. 2014. "Substituting the End for the Whole: Why Voters Respond Primarily to the Election-Year Economy." American Journal of Political Science 58 (1): 31-47.
Hellwig, Timothy, and David Samuels. 2007. "Voting in Open Economies: The Electoral Consequences of Globalization." Comparative Political Studies 40 (3): 283-306.

Jerit, Jennifer, Jason Barabas, and Toby Bolsen. 2006. "Citizens, Knowledge, and the Information Environment." American Journal of Political Science 50 (2): 266-82.

Kayser, Mark Andreas, and Arndt Leininger. 2016. "A Predictive Test of Voters' Economic Benchmarking: The 2013 German Bundestag Election." German Politics 25 (1): 106-30.

Kayser, Mark A., and Michael Peress. 2012. "Benchmarking across Borders: Electoral Accountability and the Necessity of Comparison." American Political Science Review 106 (3): 661-84.

Kiewiet, D. Roderick. 1983. Macroeconomics and Micropolitics: The Electoral Effects of Economic Issues. Chicago: University of Chicago Press.

Kramer, Gerald H. 1971. "Short-Term Fluctuations in U.S. Voting Behavior, 1896-1964.” American Political Science Review 65 (1): 131-43.

Leigh, Andrew. 2009. "Does the World Economy Swing National Elections?" Oxford Bulletin of Economics and Statistics 71 (2): 163-81.

Mink, Mark, Jan Jacobs, and Jakob de Haan. 2007. "Measuring Synchronicity and Co-movement of Business Cycles with an Application to the Euro Area." Working paper, University of Groningen.

Palmer, Harvey D., and Guy D. Whitten. 1999. "The Electoral Impact of Unexpected Inflation and Economic Growth.” British Journal of Political Science 29 (4): 623-39.

Persson, Torsten, and Guido Tabellini. 1990. Macroeconomic Policy, Credibility and Politics. New York: Harwood Academic.

Pop-Eleches, Grigore, and Joshua A. Tucker. 2011. "Communism's Shadow: Postcommunist Legacies, Values, and Behavior." Comparative Politics 43 (4): $379-408$.

Powell, G. Bingham, and Guy D. Whitten. 1993. "A Cross-National Analysis of Economic Voting: Taking Account of the Political Context." American Journal of Political Science 37 (2): 391-414.

Price, Vincent, and John Zaller. 1993. "Who Gets the News? Alternative Measures of News Reception and their Implications for Research." Public Opinion Quarterly 57 (2): 133-64.

Scheve, Kenneth. 2001. "Democracy and Globalization: Candidate Selection in Open Economies." Paper presented in the annual meeting of the American Political Science Association, San Francisco. http:// tinyurl.com/hp7t2mv.

Tucker, Joshua A. 2006. Regional Economic Voting: Russia, Poland, Hungary, Slovakia, and the Czech Republic, 1990-1999. New York: Cambridge University Press.

van der Brug, Wouter, Cees van der Eijk, and Mark N. Franklin. 2007. The Economy and the Vote: Economic Conditions and Elections in Fifteen Countries. New York: Cambridge University Press. 
Copyright of Journal of Politics is the property of University of Chicago Press and its content may not be copied or emailed to multiple sites or posted to a listserv without the copyright

holder's express written permission. However, users may print, download, or email articles for individual use. 